\title{
Elementos metapoéticos do poema "Ave inquieta” de Afonso Duarte
}

\author{
Metaphoetic elements of poem "Ave inquieta" by Afonso Duarte
}

\author{
Rodrigo Conçole Lage
}

Centro Universitário São José de Itaperuna, Bom Jesus do Itabapoana, RJ, Brasil.

\begin{abstract}
Resumo: O objetivo deste artigo é identificar alguns dos princípios teóricos que nortearam o trabalho poético do poeta português Afonso Duarte. Para isso, nós iremos estudar um de seus metapoemas, o "Ave Inquieta”, a partir das ideias de Aristóteles, Horácio, Longino e outros teóricos sobre a concisão e imitação. Por isso, dividimos nosso trabalho em duas partes. Na primeira, utilizando esse referencial teórico, procuramos definir o conceito de concisão, discutindo a sua importância. Na segunda, analisamos a questão da valorização da brevidade, do papel da poesia, do poeta e da proeminência da temática amorosa a partir da ideia de imitação da natureza.

Palavras-chave: Afonso Duarte. Concisão. Imitação. Temática Amorosa.
\end{abstract}

\begin{abstract}
The objective of this article is to identify any of theoretical principles which guided the poetical work of Portuguese poet Afonso Duarte. For that, we will study one of his metapoems, the "Ave Inquieta", from of the ideas of Aristotle, Horace, Longinus and other theoreticians about the concision and imitation. Therefore, we divided our article into two sections. In the first, using this theoretical background, we try to define the concept of concision, discussing their importance. In the second, we analyze the question of the appreciation of brevity, the role of poetry, of poet and prominence of the love theme from the idea of imitation of nature.

Keywords: Afonso Duarte. Concision. Imitation. Love Theme.
\end{abstract}

\section{Introdução}

O poeta português Joaquim Afonso Fernandes Duarte, mais conhecido como Afonso Duarte, nasceu no dia 1 de janeiro de 1884, em Ereira, e morreu na cidade de Coimbra, em 5 de Março de 1958. Foi um dos fundadores da revista Tríptico, lançada em 1924. Durante algum tempo esteve ligado ao movimento saudosista, mas a sua obra também enveredou pelos caminhos do modernismo e veio a influenciar a poesia neorrealista.

Mesmo tendo exercido um papel de certa relevância na poesia portuguesa do século $\mathrm{XX}^{2}$ é quase que totalmente desconhecido no Brasil, nunca tendo sido publicado no país. Ao mesmo tempo, ao contrário do que aconteceu com outros poetas do mesmo período, sua obra não tem sido objeto de maiores estudos acadêmicos. A constatação desse fato nos levou a escolhê-la como objeto de estudo. Mais especificamente o poema "Ave Inquieta", do livro Lápides e outros poemas (1956-1957).

Essa escolha está relacionada ao fato do texto apresentar algumas reflexões sobre o fazer poético, podemos classificá-lo como um metapoema. Esse gênero pode ser definido como um "texto poético por natureza expressivo que traz como motivo o "fazer poético" e seus desdobramentos" (ALVES, 2009, p.

\footnotetext{
${ }^{1}$ Centro Universitário São José de Itaperuna (UNIFSJ)/Universidade do Sul de Santa Catarina (UNISUL). ORCID: http://orcid.org/oooo0002-5337-4503. E-mail: rodrigo.lage@yahoo.com.br

2 O que não quer dizer que, atualmente, seja devidamente conhecido e valorizado em Portugal. Segundo Ferreira (2013, p. 56): "Ignorado por muitos, admirado por outros, esquecido por quase todos, Afonso Duarte era, ao mesmo tempo, um homem culto e profundamente ligado à terra onde nasceu".
} 
26). Ou seja, envolve todas as composições que discutem alguma questão relacionada ao fazer poético.

Analisando-o, poderemos verificar se os princípios teóricos ali presentes refletem ou não os ideais do próprio Afonso Duarte ${ }^{3}$, o que nos permitiria compreender um pouco melhor os princípios que enorteiam o seu fazer poético. Ao mesmo tempo, como ele veio a influenciar outros poetas, isso poderia ser utilizado em novos estudos para verificar se essas ideias estão ou não presentes naqueles que foram influenciados por Duarte.

O poema aqui analisado tem, como pontos centrais, dois tópicos que estão acompanhados de um ligeiro comentário sobre a natureza do poeta. São eles: uma explicação sobre a natureza de um poema breve, o que implica a sua valorização, e a presença da temática amorosa. Partindo do princípio de que a questão da brevidade é o assunto mais importante, nós vamos nos concentrar nessa questão. O que não quer dizer que, de forma complementar, deixaremos de comentar as demais.

Consequentemente, iremos dividir nosso artigo em duas partes. Na primeira, examinamos a questão da presença e da valorização da concisão na poesia da antiguidade, a partir das ideias de Aristóteles, Horácio e Longino, para compreendermos o modo como ela foi revalorizada na poesia moderna. Ao mesmo tempo, examinaremos as suas características e limitações. Na sequência, analisamos o poema de modo a identificar o modo como o assunto foi tratado e abordamos a importância da temática amorosa.

\section{Por uma definição da concisão: um exame da questão}

Ao observarmos a poesia moderna vemos que um atributo muito valorizado é a concisão. Segundo Marcelo Spalding (2008, p. 17), "A idéia de provocar

\footnotetext{
3 Para termos uma visão geral das reflexões teóricas de Afonso Duarte seria importante um estudo detalhado de todas as discussões sobre o fazer poétio presentes no conjunto de sua produção poético e nos textos em prosa em que tratou do assunto, mas isso exigiria um artigo específico sobre o assunto. Acreditamos que o estudo individual de cada texto é a melhor forma de se chegar a esse conhecimento global, evitando assim os perigos das generalizações.
}

efeitos artísticos mediante a utilização de um número limitado de elementos é talvez uma das mais frutíferas em trânsito na modernidade, numa clara reação a prolixidade e à redundância identificáveis em períodos anteriores". O que não quer dizer que a defesa da concisão em uma obra literária seja algo original.

Na Poética vemos que Aristóteles, ao defender a superioridade da imitação trágica em relação a da épica, afirma: "E, ainda, pelo fato de cumprir-se o fim da imitação numa menor extensão - pois o mais compacto agrada mais do que o diluído em muito tempo: digamos, por exemplo, que alguém pusesse o Édipo de Sófocles em tantos versos quanto tem a Ilíada" (BARRIVIERA, 2006, p. 104). Assim, a superioridade da tragédia se devia, entre outros fatores, a concisão do texto.

O que não quer dizer que a brevidade também não tenha sido, na antiguidade greco-romana valorizada no âmbito da poesia. No séc. I a.C., por exemplo, o poeta romano Quinto Horácio Flaco, na Epístola aos Pisões (333-337) escreveu: "Ou ser úteis ou deleitar querem os poetas, ou, simultaneamente, cantar alegrias e utilidades à vida. Seja breve tudo aquilo que prescreveres para que os ânimos dóceis e fiéis rapidamente compreendam e guardem os ditos" (FURLAN, 1998, p. 115).

Contudo, naquele período, ela nem sempre foi valoriza como algo positivo. Por diferentes razões Longino, em Do sublime, afirma que a concisão, em algumas situações, pode diminuir o sublime. Ele defende a ideia de que "são desprovidas de grandeza as frases extremamente ajustadas e cortadas em palavras curtas e sílabas breves, ligadas entre si como que por uma espécie de parafusos e no sítio dos cortes e das asperezas" (LONGINO, 2015, p. 97). O que não quer dizer que outros fatores não influenciem nessa desvalorização:

Outra coisa que pode diminuir o sublime são as expressões demasiado sincopadas, pois quando a grandeza é levada a uma brevidade extrema fica mutilada. Entenda-se, não me refiro às frases em que a redução é apropriada, mas àquelas que são muito curtas e aparecem retalhadas em pequenas 
partes. É que a expressão sincopada mutila o sentido, enquanto a concisão o potencia. É evidente que, ao contrário, as expressões longas ficam desprovidas de vigor se a extensão não respeitar a justa medida (LONGINO, 2015, p. 97-98).

Assim, Longino parte do princípio de que, se for excessiva, tanto a concisão quanto a abundância de palavras diminuem o sublime. De qualquer forma, por tudo o que foi dito, podemos ver que a sua valorização não é uma novidade. Os poetas modernos simplesmente retomaram um princípio da antiguidade a partir de um ponto de vista ligeiramente diferente. Isto é, o seu valor não está no fato de que irá agradar ao leitor, nem por ser uma forma de facilitar o aprendizado.

A busca pela concisão na modernidade está intimamente relacionada ao surgimento do movimento simbolista e a rejeição do parnasianismo. Envolve a busca da sugestão em lugar da descrição, muitas vezes, caindo no hermetismo. De modo que, "A estética simbolista em vez de uma linguagem directamente referencial, com que expressamente se nomeia o real, prefere a linguagem alusiva e plurissignificativa que confere um tom de mistério e de invisibilidade aos seres" (AIRES, 2009, p. 32).

O que não quer dizer que todos os poetas modernos que defendem o valor da concisão o fazem pelos mesmos motivos. A clareza e a objetividade, como atributos importantes dela, continuam a ser vistos de forma positiva por muitos poetas. Ao transformar o hermetismo, a pluralidade de sentidos e outras características semelhantes em valores positivos, em contraposição aos ideais do passado (tal como os que estão presentes em Horácio), eles abriram um novo caminho ao fazer poético, que corre paralelo ao do passado.

Ao mesmo tempo, se na antiguidade ela está relacionada à retórica, à poesia e ao teatro, na modernidade, a sua utilização vai ser estendida a outras formas de arte literária, como o conto. Ela está presente nas ideias desenvolvidas por Edgar Allan Poe e Julio Cortázar, entre outros escritores que vieram a teorizar sobre esse gênero. Por isso, outros teóricos vão estender essa valorização a qualquer gênero textual. Nesse sentido, escreveu Arthur Schopenhauer (2005, p. 93):

\begin{abstract}
Mas, sem dúvida, muitos escritores procuram esconder sua pobreza de pensamento justamente sob uma profusão de palavras.

Por conseguinte, deve-se evitar toda prolixidade e todo entrelaçamento de observações que não valem o esforço da leitura. É preciso ser econômico com o tempo, a dedicação e a paciência do leitor, de modo a receber dele o crédito de considerar o que foi escrito digno de uma leitura atenta e capaz de recompensar o esforço empregado nela. É sempre melhor deixar de lado algo bom do que incluir algo insignificante. Aplica-se acertadamente aqui a expressão de Hesíodo a metade é preferível ao todo (SCHOPENHAUER, 2005, p. 93).
\end{abstract}

Assim, comparando o que foi dito pelo filósofo alemão com o que foi dito nos textos de Aristóteles, Horácio e Longino, vemos que todos os pensadores contrapõem a concisão a prolixidade. Independentemente dos efeitos causados pela abundância de palavras eles partem do princípio de que ela tem um efeito negativo. Assim, o que se busca é "a utilização de um reduzido número de elementos para a produção de um máximo de efeito artístico" (SPALDING, 2018, p. 18).

Consequentemente, a busca pela brevidade diz respeito tanto à forma do texto quanto aos elementos de linguagem utilizados. Em uma poesia, por exemplo, no que diz respeito à forma, ela envolve o número de estrofes e de versos em cada uma delas. No que diz respeito aos elementos linguísticos, está relacionada ao tamanho do verso e a quantidade de palavras e sílabas poéticas utilizadas. O que não quer dizer que a brevidade diga respeito a esses elementos.

Ao mesmo tempo, a concisão também está presente no assunto tratado. Muitas vezes irá tratar de um sentimento, um pensamento, a descrição de uma cena ou alguma questão metapoética. O que não quer dizer que um poema breve não possa apresentar uma história. Mas, nesses casos, o poema narrativo breve irá fugir da prolixidade do poema 
épico e vai se aproximar da diegese de um conto, mais especificamente, de um miniconto.

Seja como for, acreditamos que as discussões teóricas sobre o conto e o miniconto podem contribuir para um melhor entendimento desse tipo de texto. Por tudo o que foi dito, vemos que os ideais que levam à busca da concisão variam de acordo com os valores de cada período. Assim, se quisermos conhecer o pensamento de um poeta a respeito da concisão nós devemos examinar as reflexões teóricas e/ou os metapoemas que ele escreveu sobre essa questão. O que será feito na próxima seção.

\section{Uma discussão sobre a natureza da poesia em "Ave Inquieta"}

\subsection{O poema breve como imitação da natureza}

Do ponto de vista formal "Ave inquieta", escrito em 1957, é um poema composto de uma única estrofe, com treze versos irregulares, e que não apresenta um esquema rimático regular devido à mistura de rimas emparelhadas e cruzadas, como podemos ver no seu esquema rímico: AABCDCEEDDFGF. Temos uma mistura de rimas pobres, como a dos substantivos amor e dor, e rimas ricas, como a do adjetivo breve com o substantivo ave; como podemos ver no poema logo abaixo:

\author{
Ave Inquieta \\ Poema breve \\ Como um canto de ave, \\ Ou a gota de água \\ Onde o céu se espelha; \\ Pólen da flor \\ E mel na abelha: \\ Poeta \\ Ou a Ave inquieta \\ Que canta de amor, \\ Não sei de outra dor \\ Tão bem sentida, \\ Com tanta raiz \\ $\mathrm{Na}$ fonte da vida \\ 14 de Junho, 1957 (DUARTE, 1960, p. 35).
}

O título é retomado no oitavo verso, no qual o poeta é comparado a uma ave inquieta. Se observarmos a sua estrutura, veremos que o verso central é o único composto de uma única palavra, poeta. Ela demarca a divisão temática da obra que, em seis versos, trata de cada um dos dois assuntos ligados ao seu ofício. Além disso, ao observarmos o poema de lado, vemos que ele se parece com um par de asas abertas, o que remete à ideia do poeta ser um pássaro.

Como já foi dito na introdução, o primeiro tema é a questão da concisão. Podemos dizer que ele reflete o fazer poético de Afonso Duarte diante do fato de que o próprio poema foi construído a partir desse princípio. Isto é, possui uma única estrofe de treze versos de pequena extensão. A brevidade também está presente, certa forma, em todas as composições do Lápides ${ }^{4}$. São dez poemas de duas estrofes, nove de uma, dois de quatro e um de cinco.

Ao falar sobre o poema breve o eu poético o compara a diferentes elementos da natureza: "o canto da ave (DUARTE, 1960, p. 35), "a gota de água” (DUARTE, 1960, p. 35), "o pólen da flor" (DUARTE, 1960, p. 35) e "o mel" (DUARTE, 1960, p. 35). Ou seja, parte do princípio de que ele nasce da imitação da natureza. Um conceito que, ao longo do tempo, adquiriu diferentes sentidos. Seja como for, independentemente do sentido adotado, "é um termo relacional, significando dois elementos e alguma correspondência entre eles" (ABRAMS, 2010, p. 24).

E, ao observarmos o poema, vemos que esse é o principio que norteia as comparações realizadas pelo eu poético. Isto é, podemos dizer que segue a ideia de que "o termo deixa implícito que uma obra de arte é construída conforme modelos prévios na natureza das coisas" (ABRAMS, 2010, p. 24). Para identificarmos as características de um poema breve precisamos examinar os atributos encontrados em cada um desses modelos e o modo como se apresentam no texto.

O primeiro é o gorjeio dos pássaros. Nele, a beleza é fruto da intensidade e da velocidade produzidas

4 Apesar de encontrarmos várias composições com versos longos, como a "Ode Spútnika" (DUARTE, 1960, p. 38), esses poemas têm um pequeno número de versos e estrofes. 
pela brevidade. Esse modelo já havia sido adotado anteriormente na poesia japonesa e pode ter servido de inspiração a Afonso Duarte, pois era conhecido dos portugueses: "Nunca os japoneses se interessaram pelos poemas de longa metragem, como recorda Wenceslau de Moraes. "Para eles o poema é como um gorjeio de pássaro, harmônico e rápido"” (VIEIRA, 1989, p. 37 apud AIRES, 2009, p. 97).

Consequentemente, a imitação da natureza envolve, de forma mais específica, a imitação do belo. Beleza que se atinge pela concisão do texto que passa a ter intensidade com a "eliminação de todas as ideias ou situações intermédias” (CORTÁZAR, 2008, p. 157). Isso também lhe dá dinamismo e permite que seja lido em pouco tempo, a chamada velocidade da obra. O que é importante porque a intensidade também depende da inexistência de interrupções durante leitura, o que exige que seja lido de uma assentada.

Na sequência, nos v. 3 e 4, ele é comparado a uma gota de água na qual o céu se espelha. Assim, o eu poético reforça a ideia de que a poesia é a imitação da natureza. Nesse sentido, assim como a água serve de espelho para o céu, o poema deve ser capaz de refletir o universo ao seu redor. Seu tamanho não é um impedimento para que possa tratar de algo grandioso, da mesma forma que a grandeza do céu não é um impedimento para que uma pequena gota drágua o reflita.

Na sequência, é comparado ao pólen que "é o gâmeta masculino das flores das plantas, sendo produzido pelas anteras e atraído pelo ovário com o objectivo de garantir a fecundação do mesmo e consequentemente garantir a reprodução da planta, e a sobrevivência da espécie" (CASACA, 2010, p. 4). Assim, é visto, igualmente, como algo irá ser utilizado para a fecundação na medida em que vai sendo difundido. Não tem uma finalidade meramente estética, mas é um transmissor de ideias e sensações.

Essas ideias e sensações, ao serem difundidas irão gerar frutos. Obviamente, diante do seu tamanho, o eu poético não chega a explicitar quais serão os frutos produzidos por ele. Mas, como o sétimo verso se refere à figura do poeta, de certo modo, pode estar se referindo ao nascimento de outros poetas. Assim, eles nasceriam ao serem fecundados pela leitura dos poemas. Ao mesmo tempo, ao atuar como elemento fecundante, o poema permite que todos participem da poesia.

Nesse sentido, podemos nos apropriar das palavras de Linhares Filho. Ao estudar a questão da participação na poesia na obra de Miguel Torga ele disse que, para o poeta português, “a Poesia não deve ficar represa no poeta, na Natureza ou no poema; pelo contrário, deve atingir todos os homens, para que todos se realizem na Beleza, na verdade e no Bem, e o Ser alcance a plenitude" (FILHO, 1997, p. 212). Ideia que, em Afonso Duarte, será reforçada com a utilização da poesia como alimento.

Assim, temos nos v. 6 e 7 a metáfora do "mel na abelha:/ poeta" (DUARTE, 1960, p. 35) por meio da qual vemos que, além do atuar na fecundação, o poema breve também é um alimento. É uma retomada da ideia de que a alma também se alimenta, tal como podemos ler, por exemplo, no diálogo Protágoras 313c, de Platão: "Mas do que se alimenta a alma? De conhecimentos, é claro, respondi” (PLATÃO, 2002, p. 55). O que o eu poético faz é transformar o poeta num fabricante de alimentos.

A comparação com o mel é interessante porque, assim como o mel em grande quantidade se torna enjoativo, um poema verborrágico também será. Assim, ambos devem ser consumidos com moderação, o que leva à valorização da concisão. $O$ valor do texto não está no tamanho, mas no seu conteúdo. Ao mesmo tempo, podemos associar à ideia de doçura do mel com a do canto da ave, o que remete à leveza, ao ritmo, à suavidade do poema.

Ao mesmo tempo, devemos prestar atenção na utilização dos dois pontos no final do sexto verso porque não foi uma escolha aleatória. Uma de suas funções é a de indicar ao leitor a presença de um esclarecimento que, no texto aqui estudado, se resume à palavra poeta. Assim, o eu poético deixa bem claro que a palavra abelha é uma metáfora para a figura do poeta, aquele que fabrica o poema. Na sequência, o poema passará, então, a tratar do seu ofício. 


\subsection{O poeta como um cantor do amor}

No oitavo verso, o eu poético mais uma vez compara o poeta a um elemento da natureza, mais especificamente, a uma ave que está inquieta. Como no segundo verso o poema foi comparado ao canto de uma ave, é compreensível a utilização dessa metáfora. O que merece destaque é o fato de ele ser inquieto, um adjetivo que pode ter diferentes sentidos. Pode se referir a alguém que não tem sossego, preocupado, sempre insatisfeito ou agitado. Seja qual for o estado em que se encontra, o seu estado tem como causa o amor.

Ou seja, ele não trata de qualquer assunto, não é um indivíduo politicamente engajado , é alguém "Que canta de amor (DUARTE, 1960, p. 35). Portanto, o eu poético entende que deve se voltar para o indivíduo, para uma literatura de caráter introspectivo e intimista, tal como a praticada pelo movimento presencista. Assim, apesar de Afonso Duarte ter vindo a influenciar alguns poetas neorrealistas, ele defende nesse poema o exercício de uma literatura voltada para o psicologismo de matriz presencista:

Quanto aos seus aspectos mais marcantes, o movimento da "Presença", na mesma linha do Orfismo que o precede, e contrariamente ao Neo-Realismo que o sucederá, valoriza o individual acima do social, a intuição acima da razão, o mistério acima do problema, a introspecção acima da objetividade, na direção de uma concepção metafísica da arte. Outro aspecto proeminente é o que se pode chamar de psicologismo, referido à freqüência da confissão ou da transposição ficcional da análise interior (ADERALDO, 1988, p. 189).

Por esse motivo, a literatura presencista foi acusada de ser alienada. Crítica que poderia ser dirigida ao "Ave Inquieta", que possui muitas dessas características, pois o próprio eu poético também tem em

\footnotetext{
5 O apoliticismo na poesia defendido pelo eu poético é um reflexo dos ideais do próprio poeta. Segundo Ferreira (2013, p. 40), "Nunca aderiu a qualquer movimento. Rejeitava tudo que o ligasse a 'modelos políticos', muito embora acompanhasse todos e tivesse ideias bem definidas que não deixava de expressar”.
}

mente a construção de uma obra "impelida pelos problemas da consciência individual" (ADERALDO, 1988, p. 189). De qualquer forma, isso não quer dizer que outros temas sejam excluídos, como podemos ver no fato de ter escrito um metapoema; podemos dizer que eles adquirem um caráter secundário.

Portanto, ao escrever um metapoema Afonso Duarte não foge do princípio defendido na segunda parte do poema. As reflexões teóricas da primeira parte dão o embasamento necessário para se escrever sobre o amor. Ao mesmo tempo, a defesa da proeminência da poesia amorosa faz dele um poema sobre o amor. Assim, se a imitação da natureza exterior se concretiza nos aspectos formais do texto, a temática é definida a partir da imitação da natureza interior dos homens.

Podemos, então, dizer que da mesma forma que os princípios teóricos da primeira parte refletem as suas ideias, as questões tratadas na segunda estão na mesma situação. Afonso Duarte, segundo Maria Augusta Pablo Trindade Ferreira (2013, p. 27): "Advertia, muitas vezes, para "o risco de criar poesia morta ao tocar-se em temas não vividos”. Era importante que a poesia estivesse de acordo com o pensar e sentir do poeta".

Consequentemente, o eu poético deve ser visto como sendo o próprio poeta ${ }^{6}$ e não uma figura autônoma. Pois, ao fazer essas reflexões sobre a transformação do sofrimento em matéria para a poesia ele nos apresenta os princípios que norteiam o seu fazer poético. E que estão presentes em algumas de suas composições. Essa "coerência entre a sua vida, o sentir, e a poesia só é possível em alguém que sofreu e soube transformar a dor em arte" (FERREIRA, 2013, p. 28).

Não podemos ignorar o fato de que ele não valoriza a poesia de teor subjetivista porque tem uma visão positiva do amor. O eu poético o vê de forma ambivalente. Não considera o amor algo belo, sagrado ou merecedor de ser cantado pela felicidade que traz aos homens, mas vê nele um sofrimento: "Não sei de

\footnotetext{
6 Em apoio dessa hipótese, temos a seguinte declaração de Ferreira (2013, p. 58): "Confiou unicamente à poesia as angustias de amor, talvez por ser muito cioso de sua vida particular, ou por orgulho". A experiência pessoal pode ter levado o poeta a ver o amor como uma dor e a valorizar a utilização da temática amorosa.
} 
outra dor/ Tão bem sentida," (DUARTE, 1960, p. 35). Contudo, juntamente com o sofrimento temos os benefícios trazidos pelo fato de amarmos e sermos amados.

Ao apresentar o amor como um sofrimento que o poeta, ou o eu poético, considera um benefício, ele está retomando uma ideia presente em outros autores. Nesse sentido, um dos exemplos mais famosos na poesia de língua portuguesa é o soneto de Camões intitulado "Amor é fogo que arde sem se ver":

\section{Amor é fogo que arde sem se ver}

Amor é fogo que arde sem se ver, é ferida que dói, e não se sente; é um contentamento descontente, é dor que desatina sem doer.

É um não querer mais que bem querer; é um andar solitário entre a gente; é nunca contentar-se de contente; é um cuidar que ganha em se perder.

É querer estar preso por vontade; é servir a quem vence, o vencedor; é ter com quem nos mata, lealdade.

\section{Mas como causar pode seu favor nos corações humanos amizade, se tão contrário a si é o mesmo Amor? (CAMÕES, [2006])}

O poema camoniano não só tem o amor como tema, mas também trabalha com a ideia de que ele é uma mistura de bens e de males. Contudo, isso não quer dizer que Camões tenha sido a sua fonte de inspiração. O estudo dos poetas que influenciaram Afonso Duarte talvez possa fornecer alguma indicação sobre as possíveis influências, mas isso fugiria aos limites de nosso trabalho. De qualquer forma, a falta de mais pesquisas sobre ele é um grande problema para os que desejam estudá-lo.

Por fim, o eu poético retoma a ideia de imitação ao deixar claro que a escolha do amor como tema está baseada na noção de que não existe nenhuma dor tão firmemente ancorada na vida quanto esse senti- mento. É nela que o poeta deve buscar os modelos a serem imitados, como se fosse a fonte de toda poesia, porque as raízes de cada tema estão enraizados nela. Por isso, lemos na conclusão do poema: "Com tanta raiz/ Na fonte da vida” (DUARTE, 1960, p. 35).

\section{Considerações finais}

Sendo Afonso Duarte quase que totalmente desconhecido no Brasil, nós consideramos que o estudo de sua produção poética é uma forma de se atenuar essa situação. Para isso, escolhemos como objeto de estudo um de seus metapoemas. Isso nos permitiu um melhor conhecimento de sua poesia e de suas ideias sobre o seu fazer poético.

A partir dos conceitos de brevidade e imitação analisamos o modo como ele vê a questão da concisão, a figura do poeta e valoriza a temática amorosa. Contudo, só um estudo detalhado de todos os textos que contendo reflexões sobre a teoria da poesia nos permitirá ter uma visão mais ampla do assunto. De qualquer forma, esperamos ter contribuído para que sua poesia seja mais conhecida, inspirando outros estudiosos a se dedicarem ao estudo de sua obra.

\section{Referências}

ABRAMS, M. H. O espelho e a lâmpada. São Paulo, Editora UNESP, 2010.

ADERALDO, Noemi Elisa. Acerca da 'Presença'. Revista de Letras, Fortaleza, v. 13, n. 1/2, p. 187-192, 1988. Disponível em: http://www.repositorio.ufc.br/handle/riufc/ 17394 . Acesso em: 08 jul. 2019.

AIRES, Tiago Manuel Martins. Arlindo Barbeitos: Poética da Concisão. 2009. 113 f. Dissertação (Mestrado em Literaturas Românicas, Estudos Brasileiros e Africanos) - Universidade de Lisboa, Lisboa, 2009. Disponível em: http://repositorio. ul.pt/handle/ 10451/1718. Acesso em: 04 jul. 2019. https:// doi.org/10.32385/rpmgf.v29i2.11056

ALVES, Leonardo da Silva. A profusão metapoética em Faustino. 2009. 127 f. Dissertação (Mestrado em Letras) - Universidade Federal do Rio Grande, Rio Grande, 2009. Disponível em: http://repositorio.furg.br/handle/1/2923. Acesso em: 14 nov. 2017. Acesso em: 14 jul. 2019. https:// doi.org/10.18605/2175-7275/cereus.v10n2p12-25 
BARRIVIERA, Alessandro. Poética de Aristóteles: tradução e notas. 2006. 128 f. Dissertação (Mestrado em Estudos da Linguagem) - Universidade Estadual de Campinas, Campinas, 2006. Disponível em: http://repositorio.unicamp. br/ jspui/handle/REPOSIP/268984. Acesso em: 01 jul. 2019. https://doi.org/10.34037/978-989-54295-2-3_3 8

CAMÕES. 2006 Amor é fogo que arde sem se ver. Poemas do mundo, 2006. Disponível em: https://poemasdomundo.wordpress.com/2006/06/10/amor-e-fogo-que-arde-sem-se-ver/. Acesso em: 16 jul. 2019.

CASACA, João Diogo. Manual de produção de pólen e própolis. Lisboa: FNAP - Federação Nacional dos Apicultores de Portugal, 2010. Disponível em: http://fnap.pt/projectos/ manuais-tecnicos-de-divulgacao/. Acesso em: 10 jul. 2019.

CORTÁZAR, Julio. Valise de Cronópio. São Paulo: Perspectiva, 2008.

DUARTE, Afonso. Lápides e outros poemas (1956-1957). Lisboa: Iniciativas Editorias, 1960.

FERREIRA, Maria Augusta Pablo Trindade. O poeta e o homem: Afonso Duarte. Montemor-O-Velho: Câmara Municipal de Montemor-O-Velho, 2013. Disponível em: https://issuu. com/cm_mv/docs/afonso_duarte. Acesso em: 10 jul. 2019.

FILHO, Linhares. O Poético como humanização em Miguel Torga. Fortaleza: Casa José de Alencar/UFC, 1997.

FURLAN, Mauri. Ars Traductoris: Questões de LeituraTradução da Ars Poetica de Horácio. 1998. 138f. Dissertação (Mestrado em Literatura: Teoria da Tradução) - Universidade Federal de Santa Catarina, Florianópolis, 1998. Disponível em: https://repositorio.ufsc.br/xmlui/handle/123456789/77364. Acesso em: 01 jul. 2019. https://doi.org/10.20873/uft. 2525-4863.2017v2n3p965

LONGINO, Dionísio. Do sublime. Coimbra: Imprensa da Universidade de Coimbra; São Paulo: Annablume Editora, 2015. Disponível em: https://digitalis-dsp.uc.pt/bitstream/10316.2/38162/1/Do\%2oSublime.pdf. Acesso em: 02 jul. 2019.

PLATÃO. Protágoras. Tradução de Carlos Alberto Nunes. Belém: EDUFPA, 2002.

SCHOPENHAUER, Arthur. A arte de escrever. Porto Alegre: L\&PM, 2005. Disponível em: https://archive. org/stream/SCHOPENHAUERA.AArteDeEscrever/ SCHOPENHAUER\%2C\%20A.\%20A\%2oArte\%2ode\%20 Escrever\#page/n3/mode/2up. Acesso em: 02 jul 2019.

SPALDING, Marcelo. Os cem menores contos brasileiros do século e a reinvenção do miniconto na literatura brasileira contemporânea. 2008. 81f. Dissertação (Mestrado em Literatura Brasileira, Portuguesa e Luso-Africanas) - Universidade Federal do Rio Grande do Sul, Porto Alegre, 2008. Disponível em: http://www.lume.ufrgs.br/handle/10183/13816. Acesso em: 01 jul. 2019. https://doi.org/10.35520/flbc.2014. v6n12a17304

Recebido em: 5/8/2019.
Aprovado em: 16/10/2019.

\section{\#35260 \\ SEÇÃO: ENSAIOS}

\section{Endereço de correspondência:}

Ce Governador Roberto Silveira - R. Gonçalves da Silva, $\mathrm{n}^{\mathrm{0}} 75$ - Centro, Bom Jesus do Itabapoana - RJ, 28360-000 